\title{
Introduction: Ready for use? An old medium in new times
}

Depending on the theoretical perspective and empirical evidence they draw upon, scholars and researchers have been announcing for quite a while now either the dead or the re-invigoration of television both as a social institution and economical system (Katz, 2009). Whether traditional television is believed to be on its deathbed or re-inventing itself in the face of the digital age, studies show that television is strongly affected by the developments in the field of the Internet and telecommunications, not only in technological, but also in social, cultural, political and economical terms. In this respect, the analysis of Mackay and O'Sullivan (1999) pp. 4-5, describing digital television as an 'old' medium in 'new times', captures well what television as a social institution, as an industry, as a technology and as a social-cultural practice is going through. What we witness today is the 'refashioning' and 'remediation' of a medium that tries to answer to the challenges of new media (Lister et al., 2003, pp. 39-40).

This special issue takes the transition towards a digital, interactive and/or mobile television era as its point of departure, and handles the overarching question what this means for large groups of people all over the world who are watching and making use of television. As James Bennett (2008) p. 162 argues, '[...]' television, like so much of our contemporary mediascape, is now a digital media, and we must work to theorize it as such'. Both from an interdisciplinary and international perspective, the articles in this issue cover a spectrum of different approaches to the potential, actual and forthcoming shifts of the digitization of television in the life of people. As such, they are exemplary for the diverging and converging interest in interactive, digital television (briefly IDTV) as well as mobile television.

Diverging because of the wide variety of perspectives taken. Studies in media policy, media use, information technology, media economics... all show a particular interest in the way the regulation, use and significance of television are (re-)organized in the digital era. At the same time, several forums have been established on which researchers from different academic disciplines meet industry and policymakers to reflect on television's future. Especially two of those forums are pivotal in this regard, at least from an European perspective: the European Interactive TV Conference series EuroITV (since 2003) and the five-year European COST 298 action 'Participation in the broadband society' (2005-2010). For this special issue in particular the EuroITV conference in 2009 (Leuven, Belgium) and the COST298 workshop 'Digital Television Revisited' in 2008 (Budapest, Hungary) have played a key role.

We believe that these forums are interesting meeting points as they demonstrate that in spite of their different backgrounds, perspectives and aims, many participants share a clear interest, and therefore converge, in reflecting if and how the entry of interactive, digital and mobile features in television production and distribution can and might create new potentials. In this sense for example Doug Williams, Marian Ursu, Joshan Meenowa, Pablo Cesar, Ian Kegel and Karl Bergström discuss in this issue the potential for enhanced television experience by supporting social interaction on a distance between close-knit groups. Wendy Van den Broeck, Joke Bauwens and Jo Pierson show how the possibilities of enhanced television experience are valued (or not) in personal terms, embedded in everyday practices. In a similar way, but then for mobile television, Hyunjoo Lee, Daejoong Kim, Jungho Ryu and Sungjoon Lee investigate the experiences enabled through mobile television and the consequences for adoption.

Many contributors to these forums share the pursuit of identifying, explaining and sometimes removing the obstacles that impede technologies and people to make the best of the changing television system. This basically boils down to future-making. In this particular point, views sometimes strongly diverge in accordance with ideological and political ideas, but they also converge on ascribing a key role to the user, whether as consumer (in view of market demand), citizen (with an eye to public participation and community) or co-designer (a notion which seems to combine both worlds). Although the user attracts ample attention from the fields of social-cultural (user) research, industry and policy, it is the interplay between these three spheres that helps us understand how and why the use of a new technology is not an isolated matter, but part of a wider field of interacting processes in an ecosystem. The user is always a networked user, not only in the sense of a technologically mediated individual, but also as a socially, culturally, economically and politically mediated individual. This point of view has been central to the thought of Raymond Williams (1974/2003), one of the old television theorists, and to 
many others who in his wake have studied communication technologies as social categories, both shaped by society and on their turn also shaping society (see for example Moores, 1993). This means that people's access to, usage of and participation in media technologies take place in a complex interplay of structural processes in which the exercise of power, enforcement, restrain and control collide or concur with the exercise of will, need, freedom and agency.

The special issue therefore takes a closer look at how the networked user is positioned in the broader ecosystem of socialcultural research, industry developments and policy choices regarding new television technologies in a digital society. Each of the six contributions takes one particular social sphere (social-cultural, industry and policy) as its point of departure and discusses the shift towards IDTV or mobile television from a particular point of view.

(1) From a social-cultural perspective, since the 1950s television has established itself as a daily, domestic, routine and structuring leisure activity. Families have gathered around the electronic hearth to spend their evenings at home (see Lull, 1990). On the couch millions and billions of citizens have participated in mass ceremonies and become part of national and international communities (see Scannell, 1989). For many people television programs have given food for conversation among relatives, friends, colleagues, neighbors and passers-by in shops, trains and busses (see among many others Hobson, 1989; Gillespie, 1995; Paterson et al., 1995). Studies and commentaries on the meaning of TV in people's everyday life often question if and how IDTV and mobile television will affect the medium's role in social life as, for example, in family life as a sort of intergenerational glue among parents and children, or in community life as a cross-demographic binder among different social groups (Hartley, 1999). Although empirical evidence indicates the dispersal of media use at home, as the new screens (i.e. PC, games consoles, iPad, and other handheld devices) and television peripherals (DVD players) offer an enormous array of media consumption opportunities, it is still unclear how families themselves are dealing with the bonding potential of TV in their daily routines. When it comes to national communities the number of television channels available has proliferated significantly. A vast gamut of network and terrestrial TV stations, independent satellite and cable channels, generalist and specialist TV channels, public service and commercial broadcasting channels, and pay-per-view and on-demand deliveries construct segmented audiences. In particular the simultaneity of the TV experience (watching the same program at the same moment) crumbles in the age of abundance (Lister et al., 2003, p. 30).

Within this social-cultural perspective studies on users show that it is hard to ignore the user when one tries to understand why new television technologies sometimes quickly get adopted and used, and sometimes not. The article by Hyunjoo Lee, Daejoong Kim, Jungho Ryu and Sungjoon Lee focuses on the (non) adoption of mobile television and closely examines the factors influencing young people's adoption behavior. Especially entertainment needs and portability seem to play a significant role, while information needs and newspaper reading are found to be negatively associated. The contribution by Wendy Van den Broeck, Joke Bauwens and Jo Pierson focuses on the actual use and domestication of new forms of television. Their study shows how the practice of watching television is strongly entrenched in cultural ideas about the 'value' of watching television to people's personal and social life and how this web of meanings impedes some people to make the switch to IDTV or to make use of the new applications offered by IDTV.

(2) From the perspective of technology and industry, one of the major shifts which is impacting how people watch and use television is the proliferation of different networked devices in the living room. Users already use their computer, smart phone or tablet while watching television, and many developers are exploiting this in order to create applications that enable interaction related to television content. Moreover, interactive television is moving beyond the set-top box, as connected television sets and solutions like Internet-TV and Google-TV link the traditional television with the Internet. Industry often believes that these developments, which show a move towards device divergence instead of device convergence, will change the way people experience the role of traditional television. Obviously, this still requires more profound research in human-computer interaction to understand the engagement of users with these new forms of television, especially as the medium television is embedded in a highly social setting, which is often ignored by technical developers in industry. In this respect personalized services and recommendations systems should take into account the multiple users that are often present when watching television. On the other hand, these connected devices enable social interaction over distance, facilitating communication and other remote interactions to take place through or alongside television. These socalled social TV services require a good understanding of how to support sociability between both remote and co-located users.

The special issue looks at the role of these technologies and industries as key elements in the ecosystem for understanding the social-technological reconfiguration related to new television technologies. In their article Doug Williams, Marian Ursu, Joshan Meenowa, Pablo Cesar, Ian Kegel and Karl Bergström apply multi-methodological user research for assessing the particular technological trajectory of social television use. Their user findings are then translated into system capabilities and technology challenges, valuable for further technological development. Also from the perspective of the technology industries and technology developers, Dimitri Schuurman, Katrien De Moor, Lieven De Marez and Tom Evens discuss how the industrial development process of ICT-innovations like mobile television can profit from a user centered living lab approach. This entails not only a move towards an 'interactionist' stance regarding user research but also an interest in the concept of open innovation, involving all relevant stakeholders in the value network.

(3) Besides the social-cultural perspective and the view from technological industry we also include the policy perspective. Clearly, the transitions in the policy landscape are closely linked with changes in the television industry. The audiovisual broadcasting industry and infrastructure have long been separated from other ICT industries like computers and telecommunications. However due to socio-economic, political and technological processes, these industries are gradually merging (e.g. evolution of interactive cable TV). This kind of convergence has been intensified by digitization. We notice 
how the digital and converged television technologies shape and are being shaped by government policies and industry strategies (Flichy and Libbrecht, 1995). The mutual shaping processes taking place between government policies and digital broadcasting development can be seen clearly in events such as the policies on licensing UMTS spectrum (via auctions, beauty contests etc.) and the digital dividend discussion. Government and regulatory decisions related to the digital dividend are opening up certain pathways, but closing other ones. Freeing-up of analogue airwaves on technical levels creates space for digital television services (like mobile DVB-H television), but can also create opportunities for wireless Internet (e.g. Google wifi bids in the US). At the same time we see how technological changes in industry and infrastructure have had an influence on public policy and regulation over broadcasting. This refers, for example, to the public service remit in a digital and converged media environment in comparison to the analogue monopoly situation of the past.

The final two articles in this issue discuss how new television technologies are a key issue in different international and national policy initiatives. The article by Nils Walravens and Caroline Pauwels takes the case of the HDTV standardization process to demonstrate how the European industrial policy failed. It equally identifies the lessons learned for HDTV's successor SHV (Super Hi-Vision). The authors also demonstrate how the lessons for policy makers may even be applied to 'purely' industrial standardization efforts as shown by the case of the standardization war between Blu-ray and HD DVD. The article by Maria Sourbati investigates the (not really successful) efforts to employ interactive digital television as a tool for social policy in the UK, in line with the public service remit. The digital switchover was presented as a gateway to an all inclusive information society, as interactive (government) services would also become available through this new form of television instead of only via the Internet. However her findings show that there has been too much belief that access to infrastructure can be equaled with access to services and with media literacy to use these services in an optimal way. Both of these articles highlight the importance of involving the broader ecosystem around systemic innovations regarding television technologies.

In drawing and examining the social-cultural, industry and policy processes that accompany the digitization of television, this special issue aims to contribute to a multi-faceted understanding of 'the conditions and forces that cause the changes and orient their evolution' (Buonanno, 2008, p. 59). From the empirical evidence and observation presented in the articles we learn that change is never instant, but nevertheless from time to time rapid; that structures sometimes impede change, sometimes speed it up; that television still is television to many people, and at the same time breaks free from its traditional meaning. In dealing with all these juxtapositions this special issue aims to give an informed account of how social institutions, i.e. citizens, consumers, policymakers, industrialists and engineers, are dealing with television's changes. Within a few decades this will be history, or at best, relevant source material for a historiography of digital television.

\section{References}

Bennet, J., 2008. Television studies goes digital. Cinema Journal 47 (3), 158-165.

Buonanno, M., 2008. The age of television: experiences and theories. Intellect, Bristol.

Flichy, P., Libbrecht, L., 1995. Dynamics of modern communication: the shaping and impact of new communication technologies. Sage, London.

Gillespie, M., 1995. Television, Ethnicity and Cultural Change. Routledge, London.

Hartley, J., 1999. Uses of Television. Routledge, London.

Hobson, D., 1989. Soap operas at work. In: Seiter, E., Borchers, H., Kreutzner, G., Warth, E.-M. (Eds.), Remote Control: Television, Audiences, and Cultural Power. Routledge, London/New York, pp. 150-167.

Katz, E., 2009. The end of Television? In: Katz, E., Scannell, P. (Eds.), The End of Television? Its Impact on the World (So Far). The Annals of the American Academy of Political and Social Science 625, 6-18.

Lister, M., Dovey, J., Giddings, S., Grant, I., Kelly, K., 2003. New media: a critical introduction. Routledge, London.

Lull, J., 1990. Inside Family Viewing: Ethnographic Research on Television's Audiences. Routledge, London.

Mackay, H., O'Sullivan, T. (Eds.), 1999. The Media Reader: Continuity and Transformation. Sage, London.

Moores, S., 1993. Interpreting Audiences: The Ethnography of Media Consumption. Sage, London.

Paterson, R., Petrie, D., Willis, J., 1995. Introduction. In: Petrie, D., Willis, J. (Eds.), Television and the Household: Reports from the BFI's Audience Tracking Study. BFI, London, pp. 1-7.

Scannell, P., 1989. Public service broadcasting and modern public life. Media, Culture and Society 11 (2), $135-166$.

Williams, R., 1974/2003. Television: Technology and Cultural Form. Routledge, London, New York.

Joke Bauwens Jo Pierson IBBT-SMIT,

Department of Media and Communication Studies, Vrije Universiteit Brussel, Brussels, Belgium

E-mail address: jo.pierson@vub.ac.be (Jo Pierson)

David Geerts Centre for User Experience Research K.U. Leuven, Leuven, Belgium 